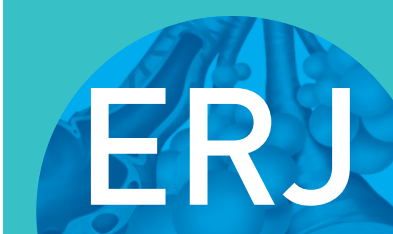

open research
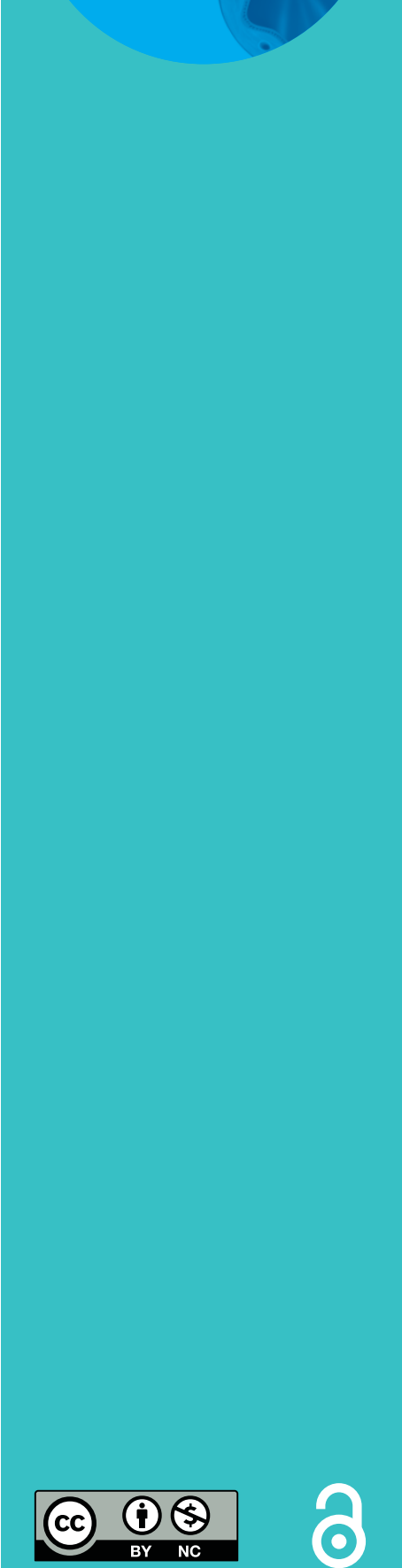

\section{Snus in pregnancy and infant birth size: a mother-child birth cohort study}

\author{
Ina Kreyberg ${ }^{1,2}, K^{2}$ atarina Hilde ${ }^{1,3}$, Karen Eline S. Bains ${ }^{1,2}$, \\ Kai-Håkon Carlsen ${ }^{1,2}$, Berit Granum ${ }^{4}$, Guttorm Haugen ${ }^{1,3}$, Gunilla Hedlin ${ }^{5,6}$, \\ Christine M. Jonassen ${ }^{7,8}$, Live S. Nordhagen (10 ${ }^{1,2,9}$, Björn Nordlund (1) ${ }^{5,6}$, \\ Corina S. Rueegg ${ }^{10}$, Katrine D. Sjøborg ${ }^{11}$, Håvard O. Skjerven ${ }^{1,2}$, Anne C. Staff $\mathbb{1}^{1,3}$, \\ Riyas Vettukattil (1) ', Karin C. Lødrup Carlsen ${ }^{1,2}$ and the PreventADALL Study \\ Group $^{12}$
}

\section{ABSTRACT}

Rationale: While recent studies show that maternal use of snus during pregnancy is increasing, the potential effects on infant birth size is less investigated, with conflicting results.

Objectives: We aimed to determine if maternal use of snus during pregnancy influences the infant anthropometric and proportional size measures at birth.

Methods: In 2313 mother-child pairs from the population-based, mother-child birth cohort PreventADALL (Preventing Atopic Dermatitis and ALLergies) in Norway and Sweden, we assessed nicotine exposure by electronic questionnaire(s) at 18 and 34 weeks of pregnancy, and anthropometric measurements at birth. Associations between snus exposure and birth size outcomes were analysed by general linear regression.

Results: Birthweight was not significantly different in infants exposed to snus in general, and up to 18 weeks of pregnancy in particular, when adjusting for relevant confounders including maternal age, gestational age at birth, pre-pregnancy body mass index, parity, fetal sex and maternal gestational weight gain up to 18 weeks. We found no significant effect of snus use on the other anthropometric or proportional size measures in multivariable linear regression models. Most women stopped snus use in early pregnancy.

Conclusion: Exposure to snus use in early pregnancy, with most women stopping when knowing about their pregnancy, was not associated with birth size. We were unable to conclude on effects of continued snus use during pregnancy because of lack of exposure in our cohort.

@ERSpublications

Snus use in pregnancy, reported by $7.1 \%$ of 2313 women, was not associated with infant birth size. As most women stopped snus use by 6 weeks gestational age, it was not possible to assess potential birth size effects of persistent use during pregnancy. http://bit.ly/2IG8Vnk

Cite this article as: Kreyberg I, Hilde K, Bains KES, et al. Snus in pregnancy and infant birth size: a mother-child birth cohort study. ERJ Open Res 2019; 5: 00255-2019 [https://doi.org/10.1183/ 23120541.00255-2019].

This article has supplementary material available from openres.ersjournals.com

Received: 18 Sept 2019 | Accepted after revision: 7 Oct 2019

Copyright $\odot$ ERS 2019. This article is open access and distributed under the terms of the Creative Commons Attribution Non-Commercial Licence 4.0. 


\section{Introduction}

Smoking during pregnancy is well established as one of the most modifiable risk factors for adverse pregnancy and infant related health effects [1], with effects related to infant birth size including increased risk of low birthweight, length and head circumference [2, 3], ponderal index [3] and being small for gestational age (SGA) [4-6]. Nonlinear decrease in mean adjusted birthweight has been observed with increasing number of cigarettes smoked per day during pregnancy $[7,8]$. Tobacco exposure may influence fetal growth throughout pregnancy, with small but significant reductions in head size and femur length in the first trimester, reduced growth after the first trimester [9] and selective reduction in abdominal circumference and muscle mass in fetuses exposed in the last trimester [10]. However, it is unclear whether these findings may be extended to smokeless tobacco.

The use of snus, a smokeless tobacco product also known as moist snuff, and other smokeless nicotine products such as electronic cigarettes have increased in recent years [11, 12], paralleling decreased smoking rates among young women in many countries [13]. A similar increased use of snus in women of reproductive age in Norway and Sweden $[12,14]$ is also shown during pregnancy $[14,15]$. We recently showed in the Preventing Atopic Dermatitis and Allergies in Children (PreventADALL) study that $11.3 \%$ of pregnant women reported use of any tobacco or nicotine products by 34 weeks of pregnancy; most commonly as snus only in $6.5 \%$, followed by cigarette smoking only in $4.1 \%$ and dual smoking and snus in $<1 \%$. Most women stopped snus use or cigarette smoking early in pregnancy, usually within pregnancy week six [16]. Nicotine from snus readily crosses the placenta into the fetal compartments and, together with its metabolites such as cotinine, concentrates in fetal blood, urine, meconium and amniotic fluid [17, 18]. Despite substantial documentation in animal models showing adverse effects in the offspring of nicotine exposure by the pregnant female, there are few studies to verify these findings in humans [19, 20]. Exposure to snus during pregnancy increased the risk of preterm birth [21], stillbirth [22, 23], oral cleft malformation [24] and neonatal apnoea [25] in Swedish Medical Birth Register studies, while altered infant heart rate variability was observed in a prospective observational study [26]. While a study from India showed an average of $87 \mathrm{~g}$ reduced birthweight (adjusted for gestational age) in infants born to women who used smokeless tobacco regularly in pregnancy [27], no significant effect of snus use was observed on birthweight in the Swedish registry study [28]. Thus, the effect of snus on birthweight is unclear, nor are we aware of studies assessing potential effects of snus use on other infant size measures at birth [19].

Therefore, we aimed to determine if maternal use of snus in pregnancy might affect infant anthropometric and proportional size measures at birth.

\section{Subjects and methods \\ Study design}

This study is based on the large population-based, prospective mother-child birth cohort PreventADALL [29], enrolling 2697 women with 2701 pregnancies and their 2397 infants born at a gestational age of $\geqslant 35.0$ weeks without serious neonatal disease. The main objectives of the PreventADALL study are to determine whether primary prevention of allergic diseases is possible through a $2 \times 2$ factorially designed, randomised trial of two interventions. Additionally, early life exposures and factors involved in allergic diseases and noncommunicable diseases are assessed. Pregnant females were recruited at the routine ultrasound screening at second trimester between gestational weeks 16 and 22, in hospitals from the general, nonselected population from the greater area of Oslo and southeast Norway as well as from the Stockholm area in Sweden between December 2014 and October 2016 [29]. Details of recruitment, inclusion and exclusion criteria are given in the supplementary material.

Affiliations: ${ }^{1}$ Faculty of Medicine, Institute of Clinical Medicine, University of Oslo, Oslo, Norway. ${ }^{2}$ Division of Paediatrics and Adolescent Medicine, Oslo University Hospital, Oslo, Norway. ${ }^{3}$ Division of Obstetrics and Gynaecology, Oslo University Hospital, Oslo, Norway. ${ }^{4}$ Dept of Toxicology and Risk Assessment, Norwegian Institute of Public Health, Oslo, Norway. ${ }^{5}$ Astrid Lindgren Children's Hospital, Karolinska University Hospital, Stockholm, Sweden. 'Dept of Women's and Children's Health, Karolinska Institutet, Stockholm, Sweden. ${ }^{7}$ Faculty of Chemistry, Biotechnology and Food Science, Norwegian University of Life Sciences, Ås, Norway. ${ }^{8}$ Genetic Unit, Centre for Laboratory Medicine, Østfold Hospital Trust, Kalnes, Norway. 9 VID Specialized University, Oslo, Norway. ${ }^{10}$ Oslo Centre for Biostatistics and Epidemiology, Oslo University Hospital and University of Oslo, Oslo, Norway. ${ }^{11}$ Dept of Obstetrics and Gynaecology, Østfold Hospital Trust, Kalnes, Norway. ${ }^{12} \mathrm{~A}$ full list of PreventADALL study group members and their affiliations can be found in the Acknowledgements section.

Correspondence: Ina Kreyberg, Division of Paediatrics and Adolescent Medicine, Oslo University Hospital and the University of Oslo, Postboks 4956 Nydalen, 0424 Oslo, Norway. E-mail: inakreybergahotmail.com 
The present study included all 2313 mother-child pairs with available exposure data of any type of nicotine or tobacco product from electronic questionnaires at 18 and/or 34 weeks of pregnancy and whose included singleton newborn babies had anthropometric measurements performed at birth (supplementary figure S1).

Maternal written consent was obtained upon primary enrolment and signed by both parents at newborn inclusion. The PreventADALL study was approved by the regional committees for medical and health research ethics in South-Eastern Norway (2014/518) and in Sweden (2014/2242-31/4).

\section{Subjects}

Baseline characteristics among the included and the excluded study participants were similar, except for marital status, previous smoking history and gestational age at birth as shown in supplementary table S1.

\section{Methods}

From electronic questionnaires completed by the women at 18 and 34 weeks of pregnancy, we collected detailed information about snus, cigarette smoking, nicotine replacement therapy (NRT) or electronic cigarettes: never, ever, prior to pregnancy, and during pregnancy up to 18 weeks and from 18 weeks to 34 weeks [16]. Background characteristics and history of previous and present pregnancies were obtained from the 18-week questionnaire and a brief interview at enrolment. Whether the women reported the ultrasound-corrected gestational age or calculated gestational age from their last menstrual period is not known. Study personnel measured maternal weight and height at the 18 -week inclusion visit. Pre-pregnancy weight was obtained by self-report rather than by objective measures.

Dedicated trained study personnel using a non-elastic measuring tape performed infant anthropometric measures within the first $24 \mathrm{~h}$ after delivery. We report the mean of two left upper arm circumference measures midway between the acromial and olecranon process, and the mean of three thoracic and abdominal circumference measures performed at end-expiration when possible. For the thoracic circumference measures we placed the lower part of the measuring tape in line with the most caudal part of the xyphoid process. For the abdominal circumference measures the lower end of the measuring tape was placed in line with the cranial part of the umbilicus. All values were recorded in centimetres with one decimal, and mean values were calculated and rounded when appropriate. Background for the methods used is described in the supplementary material. Birthweight, length (crown-heel) and head circumference as well as placenta weight was collected from the hospital records. Placenta was weighed and recorded by the midwives within $30 \mathrm{~min}$ of delivery according to hospital guidelines.

\section{Outcomes, exposures and covariates}

The main outcome was birthweight (in grams). Secondary anthropometric outcomes were birth length, head circumference, thoracic circumference, abdominal circumference and left mid upper arm circumference (all in centimetres), while the ratios of abdominal circumference to head circumference, thoracic circumference to head circumference, thoracic circumference to abdominal circumference and finally birthweight to placenta weight were proportional size outcomes.

The main exposure variables were based on any use of snus and/or smoke in pregnancy categorised into never in pregnancy ("never"), snus alone in pregnancy ("snus only") and smoking including dual snus users in pregnancy ("smoke/dual"). To differentiate between early and late snus exposure, we also separated the snus only group into "snus only 18 weeks" and "snus only 34 weeks". Women who reported ever-use of snus and/or smoking before pregnancy were included in the never group representing never-use during pregnancy. As only four women reported using NRT or electronic cigarettes, of whom three stopped when recognising pregnancy, they were included in the analyses based upon their use of snus and cigarette smoking.

Potential covariates were based upon factors previously shown to be associated with snus use in pregnancy [16] including maternal age, marital status, previous smoking history, in utero smoking exposure of the index women and living area. Additionally, we included factors possibly associated with birth size of the baby such as maternal education, pre-pregnancy body mass index (BMI), parity, fetal sex and gestational age at delivery (days). Further, as smoking cessation during pregnancy may cause weight gain [30, 31], we performed sensitivity analyses including adjustment for maternal gestational weight gain from pre-pregnancy to 18 weeks of pregnancy. The gestational age was based on femur length obtained at the routine second trimester ultrasound, as described previously [29].

\section{Statistical analysis}

Categorical variables are presented as numbers and percentages, and continuous variables as means with standard deviation or $95 \%$ confidence intervals. Differences between categorical variables were analysed by Chi-squared test and numerical data by one-way ANOVA tests. 
Associations between snus exposure and birth size outcomes were analysed using univariable and multivariable linear regression models with the birth outcomes as dependent variable and snus use as independent variable. The group of never snus users were defined as the reference group. In the multivariable models we included all covariates that were known potential confounders associated with snus use from our previous study [16] and the literature in general. Significant covariates with a p-value $<0.05$ were kept in the final models, as appropriate for each outcome, with details given in supplementary table S3. Sensitivity analyses including adjustment for maternal gestational weight gain from pre-pregnancy to 18 weeks of pregnancy were performed in case of significant associations between snus use and the respective birth outcome.

The significance level was set to $5 \%$. Because of low numbers of missing data we performed complete case analysis only. All analyses were performed using SPSS Statistics (version 25; IBM, Chicago, IL, USA).

\section{Results}

Most women (89.1\%) reported never-use of tobacco products during pregnancy, while 150 (6.5\%) reported snus only and $102(4.4 \%)$ reported cigarette smoking, including $15(0.6 \%)$ dual users. Up to 18 weeks of pregnancy $138(6.0 \%)$ women used snus only at some time or current, and $12(0.6 \%)$ up to 34 weeks. The majority $(>90 \%)$ of the snus and smoking/dual-using women stopped within pregnancy week six. Exposure to nicotine products was similar in term and preterm infants, as described in detail in the supplementary material and table S2.

The exposure groups never, snus only and smoke/dual differed significantly from each other with respect to gestational age at birth, maternal age, maternal gestational weight gain, parity and socioeconomic factors, as listed in table 1.

Unadjusted analyses showed no significant difference in birthweight among the women who used snus only compared to never and smoke/dual users (table 2). We observed significantly higher birthweight in infants exposed to snus only up to 18 weeks (table 3) after adjusting for parity, gestational age at birth, fetal sex, pre-pregnancy BMI and maternal age in multivariable regression analyses. However, after adjusting for maternal gestational weight gain (from pre-pregnancy to gestational week 18), the associations were no longer statistically significant in sensitivity analyses (table 3 ). We found no significant interaction between gestational weight gain and the tobacco exposure groups.

For the "snus up to 34 weeks" group, there was a nonsignificant trend of decreased birthweight.

The only other anthropometric measure with significant associations to snus exposure in unadjusted (table 2) and adjusted regression analyses (supplementary table S4) was head circumference. However, after adjusting for maternal gestational weight gain (from pre-pregnancy to gestational week 18) in sensitivity analyses, the association was no longer significant. We found no other significant associations between snus exposure in the univariable or multivariable regression analyses on anthropometric (supplementary table S4) or proportional size outcomes (supplementary table S5).

\section{Discussion}

In our cohort, in which $90 \%$ of the women stopped snus use at recognised pregnancy, snus exposure was not significantly associated with birthweight or other anthropometric or proportional size measures.

To our knowledge, this is the first prospective mother-child cohort study showing that the use of snus in pregnancy was not associated with infant birth size. Our results are supported by registry studies showing that women who quit snus early in pregnancy had the same risk of SGA or low birthweight of the baby as non-snus users [28, 32]. This is in contrast to an Indian cohort study of 1217 women interviewed during months 3-7 of pregnancy at house-to-house visits showing an average of $105 \mathrm{~g}$ lower birthweight among the $17 \%$ reporting daily use of chewable tobacco for $\geqslant 6$ months [27]. However, there are important differences between the studies in regards to types of smokeless tobacco products, prevalence of exposures as well as probable cultural and sociodemographic differences. In view of the presumably low total in utero nicotine exposure in our study, with most women stopping in early pregnancy, our findings are in line with other studies showing that early cessation attenuates the effects of snus [32] or smoking [7].

The apparently higher birthweight in infants born to mothers using snus up to 18 weeks of pregnancy only, before adjusting for maternal weight gain, is in contrast to registry studies from Sweden, where nonsignificant reductions in birthweight were observed in sibling analyses [28]. However, sensitivity analyses showed that the significantly higher maternal gestational weight gain in those stopping snus use compared to non-users largely explained the difference in the model not adjusting for weight gain. We are unaware of studies including maternal gestational weight gain in their adjusted models, but propose that maternal gestational weight gain should be included in analyses exploring potential effects of nicotine 


\begin{tabular}{|c|c|c|c|c|c|}
\hline & \multirow[t]{2}{*}{ Subjects } & \multicolumn{4}{|c|}{ Tobacco exposure during pregnancy } \\
\hline & & Never & Snus only & Smoke/dual & p-value \\
\hline Subjects & 2313 & $2061(89.1)$ & $150(6.5)$ & $102(4.4)$ & \\
\hline Fetal sex male & & $1097(53.0)$ & $73(48.7)$ & $50(48.5)$ & 0.37 \\
\hline Gestational age at birth & 2274 & & & & \\
\hline Weeks & & $39.2 \pm 1.7$ & $39.6 \pm 1.7$ & $38.9 \pm 1.7$ & 0.001 \\
\hline Days & & $274.7 \pm 11.6$ & $277.5 \pm 11.7$ & $272.0 \pm 11.8$ & 0.001 \\
\hline Placenta weight g & 1740 & $656 \pm 135.1$ & $679 \pm 110.2$ & $643 \pm 144.9$ & 0.12 \\
\hline \multicolumn{6}{|l|}{ Maternal factors } \\
\hline Age years & 2313 & $32.6 \pm 4.1$ & $30.9 \pm 3.2$ & $32.0 \pm 4.8$ & $<0.001$ \\
\hline Pre-pregnancy BMI & 2252 & $23.1 \pm 3.6$ & $22.8 \pm 3.5$ & $23.9 \pm 4.7$ & 0.05 \\
\hline $\mathrm{BMI}$ at 18 weeks & 2278 & $24.8 \pm 3.6$ & $24.8 \pm 3.6$ & $25.8 \pm 4.8$ & 0.016 \\
\hline Weight pre-pregnancy kg & 2263 & $65.4 \pm 11.1$ & $64.8 \pm 11.1$ & $66.4 \pm 13.4$ & 0.55 \\
\hline Weight at inclusion $\mathrm{kg}$ & 2288 & $70.1 \pm 11.1$ & $70.4 \pm 11.4$ & $71.6 \pm 13.5$ & 0.37 \\
\hline Gestational weight gain up to 18 weeks $\mathrm{kg}$ & 2259 & $4.7 \pm 3.2$ & $5.4 \pm 3.5$ & $5.3 \pm 3.8$ & 0.002 \\
\hline \multicolumn{6}{|l|}{ Pregnancy history } \\
\hline Current in vitro fertilisation & 2300 & $173[8.4]$ & $4(2.7)$ & $0(0.0)$ & $<0.001$ \\
\hline Miscarriage (s) $<12$ weeks & 2300 & & & & 0.08 \\
\hline 0 & & $1531(74.3)$ & $126(84.0)$ & 73 (70.9) & \\
\hline 1 & & $371(18.0)$ & $15(10.0)$ & $20(19.4)$ & \\
\hline$>1$ & & $146(7.1)$ & $9(6.0)$ & $10(9.7)$ & \\
\hline Miscarriage(s)/stillbirths 12-23 weeks & 2300 & & & & 0.006 \\
\hline 0 & & 2006 (97.9) & 148 (98.7) & $96(94.1)$ & \\
\hline 1 & & $41(2.0)$ & 2 (1.3) & $5(4.9)$ & \\
\hline$>1$ & & $1(0.0)$ & $0(0.0)$ & $1(1.0)$ & \\
\hline Parity & 2150 & & & & 0.008 \\
\hline 0 & & $1124(59.2)$ & $107(71.8)$ & 59 (57.8) & \\
\hline 1 & & $612(32.2)$ & $36(24.2)$ & $29(28.4)$ & \\
\hline$>1$ & & $163(8.6)$ & $6(4.0)$ & 14 (13.7) & \\
\hline \multicolumn{6}{|l|}{ Sociodemographic factors } \\
\hline Education & 2141 & & & & $<0.001$ \\
\hline Preliminary school only & & $13(0.7)$ & $1(0.7)$ & $2(2.0)$ & \\
\hline High school only & & 175 (9.3) & 19 (12.8) & 25 (24.5) & \\
\hline Higher education $<4$ years & & $580(30.7)$ & $60(40.5)$ & $42(41.2)$ & \\
\hline Higher education $\geqslant 4$ years & & $1122(59.3)$ & $67(45.3)$ & 33 (32.4) & \\
\hline Other & & $1(0.1)$ & $1(0.7)$ & $0(0.0)$ & \\
\hline Country of origin & 2150 & & & & 0.005 \\
\hline Norway and Sweden & & $1683(88.6)$ & $144(96.6)$ & 87 (85.3) & \\
\hline Rest of the world & & $216(11.4)$ & $5(3.4)$ & $15(14.7)$ & \\
\hline Marital status & 2150 & & & & $<0.001$ \\
\hline Married & & $816(43.0)$ & $39(26.2)$ & $30(29.4)$ & \\
\hline Cohabitants & & $1037(54.6)$ & $107(71.8)$ & $66(64.7)$ & \\
\hline Single & & $30(1.6)$ & 2 (1.3) & $5(4.9)$ & \\
\hline Divorced/separated & & $1(0.1)$ & $0(0.0)$ & $0(0.0)$ & \\
\hline Other & & $15(0.8)$ & $1(0.7)$ & $1(1.0)$ & \\
\hline Living area & 2150 & & & & 0.026 \\
\hline City, densely populated & & 716 (37.7) & $76(51.0)$ & $42(41.2)$ & \\
\hline City, less densely populated & & 732 (38.5) & $52(34.9)$ & $33(32.4)$ & \\
\hline Suburb & & $311(16.4)$ & $15(10.1)$ & $17(16.7)$ & \\
\hline Countryside, village & & $100(5.3)$ & 5 (3.4) & $5(4.9)$ & \\
\hline Countryside, outside village & & $40(2.1)$ & $1(0.7)$ & $5(4.9)$ & \\
\hline Household income & 2150 & & & & $<0.001$ \\
\hline Low & & $18(0.9)$ & $3(2.0)$ & 4 (3.9) & \\
\hline Middle & & $991(52.2)$ & $87(58.4)$ & $72(70.6)$ & \\
\hline High & & $857(45.1)$ & 57 (38.3) & $24(23.5)$ & \\
\hline Not reported & & 33 (1.7) & 2 (1.3) & $2(2.0)$ & \\
\hline \multicolumn{6}{|l|}{ Smoking history } \\
\hline Previous smoking & 2150 & $300(14.6)$ & $75(50.0)$ & 100 (98.0) & $<0.001$ \\
\hline
\end{tabular}




\section{TABLE 1 Continued}

\begin{tabular}{|c|c|c|c|c|c|}
\hline & \multirow[t]{2}{*}{ Subjects } & \multicolumn{4}{|c|}{ Tobacco exposure during pregnancy $\#$} \\
\hline & & Never & Snus only & Smoke/dual & p-value \\
\hline In utero exposure to cigarette smoke & 2150 & & & & $<0.001$ \\
\hline No & & 1463 (77.0) & $87(58.4)$ & $73(71.6)$ & \\
\hline Yes & & $256(13.5)$ & 29 (19.5) & $21(20.6)$ & \\
\hline Do not know & & $180(9.5)$ & $33(22.1)$ & $8(7.8)$ & \\
\hline \multicolumn{6}{|c|}{$\begin{array}{l}\text { Data are presented as } n, n(\%) \text { or mean } \pm \text { SD, unless otherwise stated. BMI: body mass index. \#: includes } \\
\text { four females who answered "yes" to ever-use of other nicotine products (nicotine replacement therapy or } \\
\text { electronic cigarettes); one was a daily user during pregnancy at } 18 \text { weeks and three quit when recognising } \\
\text { pregnancy. }\end{array}$} \\
\hline
\end{tabular}

exposure in utero on fetal growth. This is supported by studies showing an increased risk of excess gestational weight gain from pre-pregnancy to delivery when quitting smoking in pregnancy compared to non-smokers [30, 31] and substantially lower rate of neonatal birthweight below the 10th percentile [33]. However, we are unaware of studies on maternal gestational weight gain after snus cessation during pregnancy.

We were unable to conclude on the effects of continuous snus exposure through pregnancy up to 34 weeks, with only 11 subjects in this exposure group. Thus, the potential effect of continued use of snus throughout pregnancy is still uncertain. We did see a nonsignificant trend of decreased birthweight in this group, which is in line with the Indian study of smokeless tobacco [27], as well as in conventional [32], but not in sibling analyses in the Swedish birth registry study [26].

TABLE 2 Anthropometric measures and proportional size are given by tobacco exposure groups for 2313 newborn infants

\begin{tabular}{|c|c|c|c|c|c|}
\hline & \multirow[t]{2}{*}{ Subjects } & \multicolumn{4}{|c|}{ Tobacco exposure during pregnancy ${ }^{\#}$} \\
\hline & & Never & Snus only & Smoke/dual & p-value \\
\hline $\begin{array}{l}\text { Anthropometric } \\
\text { measures }\end{array}$ & & 2061 (89.1) & $150(6.5)$ & $102(4.4)$ & \\
\hline Birthweight g & 2252 & 3577 (3556-5598) & 3662 (3591-3733) & 3575 (3472-3678) & 0.11 \\
\hline Length $\mathrm{cm}$ & 2181 & $50.5(50.4-50.6)$ & $50.8(50.4-51.1)$ & $50.4(49.9-50.9)$ & 0.26 \\
\hline Head circumference $\mathrm{cm}$ & 2238 & $35.2(35.1-35.3)$ & $35.5(35.3-35.8)$ & $35.3(34.9-35.6)$ & 0.029 \\
\hline $\begin{array}{l}\text { Thoracic } \\
\quad \text { circumference } \mathrm{cm}\end{array}$ & 2157 & $34.0(33.9-34.1)$ & $34.2(33.9-34.5)$ & $34.2(33.7-34.7)$ & 0.30 \\
\hline $\begin{array}{l}\text { Abdominal } \\
\text { circumference } \mathrm{cm}\end{array}$ & 2156 & $32.8(32.7-32.8)$ & $32.9(32.5-33.3)$ & $32.7(32.2-33.2)$ & 0.79 \\
\hline $\begin{array}{l}\text { Left mid upper arm } \\
\text { circumference } \mathrm{cm}\end{array}$ & 2166 & $11.1(11.1-11.2)$ & $11.3(11.2-11.5)$ & $11.2(11.0-11.4)$ & 0.15 \\
\hline \multicolumn{6}{|l|}{ Proportional size } \\
\hline $\begin{array}{l}\text { Abdominal/head } \\
\text { circumference }\end{array}$ & 2102 & $0.94(0.93-0.94)$ & $0.92(0.92-0.94)$ & $0.93(0.91-0.94)$ & 0.45 \\
\hline $\begin{array}{l}\text { Thoracic/abdominal } \\
\text { circumference }\end{array}$ & 2151 & 1.04 (1.037-1.04) & 1.04 (1.04-1.05) & $1.05(1.04-1.06)$ & 0.14 \\
\hline $\begin{array}{l}\text { Thoracic/head } \\
\text { circumference }\end{array}$ & 2103 & 0.97 (0.965-0.97) & $0.96(0.96-0.97)$ & $0.97(0.96-0.98)$ & 0.68 \\
\hline $\begin{array}{l}\text { Birthweight/placenta } \\
\text { weight }\end{array}$ & 1729 & $5.6(5.5-5.7)$ & $5.5(5.4-5.7)$ & $5.7(5.5-6.0)$ & 0.54 \\
\hline
\end{tabular}

Data are presented as $\mathrm{n}(\%), \mathrm{n}$ or mean $(95 \% \mathrm{CI})$, unless otherwise stated. The reference group "never" includes all females who did not report use of tobacco or nicotine during pregnancy. The "smoke/dual" group includes dual smokers and snus users during pregnancy. Most of these subjects (>90\%) quit snus use or smoking by 6 weeks of pregnancy. ": includes four females who answered "yes" to ever-use of other nicotine products (nicotine replacement therapy or electronic cigarettes); one was a daily user during pregnancy at 18 weeks and three quit when recognising pregnancy. 
TABLE 3 Linear regression analyses: effect of tobacco exposure during pregnancy on birthweight (grams)

\begin{tabular}{|c|c|c|c|c|c|c|c|c|c|c|c|c|}
\hline & \multicolumn{3}{|c|}{ Univariable } & \multicolumn{3}{|c|}{ Multivariable $^{\#}(1-5)$} & \multicolumn{3}{|c|}{ Univariable sensitivity analyses } & \multicolumn{3}{|c|}{$\begin{array}{l}\text { Multivariable sensitivity analyses } \\
\qquad(1-6)\end{array}$} \\
\hline & $\begin{array}{l}\text { Subjects } \\
n\end{array}$ & B $(95 \% \mathrm{CI})$ & p-value & $\begin{array}{c}\text { Subjects } \\
n\end{array}$ & B $(95 \% \mathrm{CI})$ & p-value & $\begin{array}{l}\text { Subjects } \\
n\end{array}$ & B $(95 \% \mathrm{CI})$ & p-value & $\begin{array}{l}\text { Subjects } \\
n\end{array}$ & B (95\% CI) & p-value \\
\hline $\begin{array}{l}\text { Tobacco } \\
\text { exposure }\end{array}$ & & & 0.085 & & & 0.113 & & & 0.110 & & & 0.550 \\
\hline Never & 1772 & Ref. & & 1772 & Ref. & & 1694 & Ref. & & 1694 & Ref. & \\
\hline Snus only & 143 & $91.3(10.1-172.5)$ & & 143 & $78.1(4.7-151.5)$ & & 137 & $88.8(5.6-172.0)$ & & 137 & $\begin{array}{c}36.3 \\
(-37.4-110.0)\end{array}$ & \\
\hline Smoke/dual & 97 & $\begin{array}{c}-6.5 \\
(-103.9-90.9)\end{array}$ & & 97 & $\begin{array}{c}11.0 \\
(-76.6-98.6)\end{array}$ & & 90 & $\begin{array}{c}-5.0 \\
(-106.4-96.4)\end{array}$ & & 90 & $\begin{array}{c}-20.1 \\
(-109.1-68.9)\end{array}$ & \\
\hline $\begin{array}{l}\text { Tobacco } \\
\text { exposure }\end{array}$ & & & 0.120 & & & 0.032 & & & 0.180 & & & 0.250 \\
\hline Never & 1772 & Ref. & & 1772 & Ref. & & 1694 & Ref. & & 1694 & Ref. & \\
\hline $\begin{array}{l}\text { Snus only up to } \\
18 \text { weeks }\end{array}$ & 132 & $\begin{array}{c}102.0 \\
(17.7-186.3)\end{array}$ & & 132 & $\begin{array}{c}100.0 \\
(23.9-176.1)\end{array}$ & & 127 & $96.8(10.6-183.0)$ & & 127 & $\begin{array}{c}53.8 \\
(-22.6-130.1)\end{array}$ & \\
\hline $\begin{array}{l}\text { Snus only up to } \\
34 \text { weeks }\end{array}$ & 11 & $\begin{array}{c}-36.4 \\
(-318.9-246.1)\end{array}$ & & 11 & $\begin{array}{c}-183.1 \\
(-436.5-70.3)\end{array}$ & & 10 & $\begin{array}{c}-13.1 \\
(-310.3-284.1)\end{array}$ & & 10 & $\begin{array}{c}-180.6 \\
(-440.6-79.5)\end{array}$ & \\
\hline Smoke/dual & 97 & $\begin{array}{c}-6.5 \\
(-103.9-90.9)\end{array}$ & & 97 & $\begin{array}{c}10.9 \\
(-76.7-98.4)\end{array}$ & & 90 & $\begin{array}{c}-5.0 \\
(-106.4-96.4)\end{array}$ & & 90 & $\begin{array}{c}-20.0 \\
(-108.9-69.0)\end{array}$ & \\
\hline \multicolumn{13}{|c|}{$\begin{array}{l}\text { The reference group "never" includes all females who did not report use of tobacco or nicotine during pregnancy. The "smoke/dual" group includes dual smokers and snus users during } \\
\text { pregnancy, of whom most quit before } 6 \text { weeks of pregnancy. The nonsignificant global p-values for snus-only and smoke/dual indicate that no significant associations were observed with } \\
\text { birthweight. Covariates used in multivariable analyses: } 1=\text { parity, } 2=\text { gestational age at birth, } 3=\text { fetal sex, } 4=\text { pre-pregnancy body mass index, } 5=\text { maternal age, } 6=\text { gestational weight gain up } \\
\text { to } 18 \text { weeks of pregnancy. Ref.: reference value. ": the results of the multivariable analyses restricted by the same study population as in the sensitivity analyses without adjusting for } \\
\text { gestational weight gain, were similar in both populations (data not shown). }\end{array}$} \\
\hline
\end{tabular}


To our knowledge, this is the first study to investigate the potential effect of snus exposure in pregnancy on anthropometric and proportional size measures at birth. Birth size is determined by genetic predisposition and by the intrauterine environment, including potential unfavourable in utero exposures affecting fetal growth [34]. While birthweight and length are predictors of lean mass [35], abdominal circumference may indicate level of fat and/or size of the liver [34], and upper mid arm circumference predicts muscle mass [36]. Our study with predominantly early transient exposure to snus was not able to replicate the adverse effects on differential fetal growth by exposure to cigarette smoke $[2,3,10]$.

The study is strengthened by the prospective design, specifically designed questionnaires completed at 18 and 34 weeks of pregnancy with detailed information on the use of products containing nicotine during pregnancy and time of cessation specified by 2 -week intervals. The study provides standardised detailed anthropometric measurements conducted by trained study personnel within the first $24 \mathrm{~h}$ after delivery.

The high early pregnancy cessation rates of both snus use and cigarette smoking in this study is clearly positive for maternal and infant health, but limited our ability to study the effects of persistent use during pregnancy. Nevertheless, it provides important information for pregnant women who have stopped using snus or are planning to quit, as well as for health professionals providing their prenatal care, that early exposure does not seem to affect the birth size of the baby. In addition, detailed information of frequency of use and number of snus portions and/or cigarettes smoked among those who stopped when recognising their pregnancies are lacking, thus limiting the possibilities to assess dose-response effects. Our data are based on self-reports with no objective validation of nicotine or cotinine levels during pregnancy. Nevertheless, studies have shown that self-reports represent valid markers for tobacco exposure [37, 38]. There is uncertainty regarding the exact pregnancy week of self-reported cessation, as we do not know if the subjects reported the ultrasound corrected gestational age or the calculated gestational age from the last menstrual period. If the reported gestational age was the latter, the first two pregnancy weeks correspond with the last 2 weeks before conception, thus nicotine exposure to the offspring might be limited. The gestational age was determined based upon the routine ultrasound examination, as described in the supplementary material, with a potential variation that could not be accounted for in the present analyses. Additionally, we only adjust for weight gain in the first 18 weeks of pregnancy, since we do not have weight of the mothers at delivery. However, since most women stopped using snus by pregnancy week six, one might assume the weight gain effect related to cessation might be in the period up to 18 weeks of pregnancy. Although the participants were recruited from a nonselected general population, the educational level in our study was higher than in the Norwegian general population [29]. However, this is unlikely to impact the prevalence of snus use, since we have recently found that educational level is not associated with snus use during pregnancy [16]. It might affect the choice of lifestyle and diet, potentially influencing fetal growth. As this is a prospective cohort study, nonparticipation cannot be associated with the outcome. Therefore, effect estimates of snus use on birth outcomes should not be biased [39]. Potential covariates such as pre-eclampsia, gestational diabetes or other relevant maternal diseases that possibly could explain birth size were unavailable at the time of analyses.

\section{Conclusion}

Maternal snus use in pregnancy, with most subjects stopping when knowing about their pregnancy, was not significantly associated with birthweight or anthropometric or proportional size measures of the newborn infants. Due to low prevalence of snus users up to 34 weeks of gestation, we could not conclude on potential effects of continued snus exposure in pregnancy on infant birth size.

Author contributions: All authors have contributed substantially to the design and/or clinical follow-up of the PreventADALL study, and have revised the work critically for important intellectual content and approved the final version before submission.

Acknowledgements: PreventADALL study group: Anna Asarnoj (Astrid Lindgren Children's Hospital, Karolinska University Hospital, and Dept of Women's and Children's Health, Karolinska Institutet, Stockholm, Sweden), Oda C. Lødrup Carlsen (Division of Paediatrics and Adolescent Medicine, Oslo University Hospital, Oslo, Norway), Åshild Wik Despriée (Faculty of Medicine, Institute of Clinical Medicine, University of Oslo, the Division of Paediatrics and Adolescent Medicine, Oslo University Hospital, and VID Specialized University, Oslo, Norway), Kim A. Endre (Faculty of Medicine, Institute of Clinical Medicine, University of Oslo, the Division of Paediatrics and Adolescent Medicine, and Dept of Dermatology, Oslo University Hospital, Oslo, Norway), Peder A. Granlund (Faculty of Medicine, Institute of Clinical Medicine, University of Oslo, and the Division of Paediatrics and Adolescent Medicine, Oslo University Hospital, Oslo, Norway), Hrefna K. Gudmundsdóttir (Faculty of Medicine, Institute of Clinical Medicine, University of Oslo, and the Division of Paediatrics and Adolescent Medicine, Oslo University Hospital, Oslo, Norway), Henrik Holmstrøm (Faculty of Medicine, Institute of Clinical Medicine, University of Oslo, and the Division of Paediatrics and Adolescent Medicine, Oslo University Hospital, Oslo, Norway), Geir Håland (Faculty of Medicine, Institute of Clinical Medicine, University of Oslo, and the Division of Paediatrics and Adolescent Medicine, Oslo University Hospital, Oslo, Norway), Caroline-Aleksi O. Mägi (Astrid Lindgren Children’s Hospital, Karolinska University Hospital, and Dept of 
Women's and Children's Health, Karolinska Institutet, Stockholm, Sweden), Unni C. Nygaard (Dept of Toxicology and Risk Assessment, Norwegian Institute of Public Health, Oslo, Norway), Eva Maria Rehbinder (Faculty of Medicine, Institute of Clinical Medicine, University of Oslo, the Division of Paediatrics and Adolescent Medicine, and Dept of Dermatology, Oslo University Hospital, Oslo, Norway), Knut Rudi (Faculty of Chemistry, Biotechnology and Food Science, Norwegian University of Life Sciences, Ås, Norway), Carina M. Saunders (Faculty of Medicine, Institute of Clinical Medicine, University of Oslo, and Division of Paediatrics and Adolescent Medicine, Oslo University Hospital, Oslo, Norway), Ingebjørg Skrindo (Dept of Ear, Nose and Throat, Akershus University Hospital, Lørenskog, Norway), Cilla Söderhäll (Astrid Lindgren Children's Hospital, Karolinska University Hospital, and Dept of Women's and Children's Health, Karolinska Institutet, Stockholm, Sweden), Sandra G. Tedner (Astrid Lindgren Children's Hospital, Karolinska University Hospital, and Dept of Women's and Children's Health, Karolinska Institutet, Stockholm, Sweden), Magdalena R. Værnesbranden (Faculty of Medicine, Institute of Clinical Medicine, University of Oslo, Oslo, and Dept of Obstetrics and Gynaecology, Østfold Hospital Trust, Kalnes, Norway) and Johanna Wiik (Dept of Obstetrics and Gynaecology, Østfold Hospital Trust, Kalnes, Norway, and Dept of Obstetrics and Gynaecology, Institute of Clinical Sciences, Sahlgrenska Academy, Gothenburg, Sweden).

The study was performed within the ORAACLE group (the Oslo Research Group of Asthma and Allergy in Childhood; the Lung and Environment). We sincerely thank all the study participants and the individuals involved in facilitating and running the study, especially Ann Berglind, Malén Gudbrandsgard, Mari Rønning Kjendsli, Natasha Sedergren, Päivi Söderman and Ellen Tegnerud.

This study is registered at www.clincialtrials.gov with identifier number NCT02449850.

Support statement: The study was funded by the Regional Health Board South East, the Norwegian Research Council, Oslo University Hospital, the University of Oslo, Health and Rehabilitation Norway, and Østfold Hospital Trust; by unrestricted grants from the Norwegian Association of Asthma and Allergy, the Kloster Foundation, the Norwegian Society of Dermatology and Venerology, Arne Ingel's Legat, Fürst Medical Laboratory, the Foundation for Healthcare and Allergy Research in Sweden (Vårdalstiftelsen), Swedish Asthma and Allergy Association's Research Foundation, the Swedish Research Council Initiative for Clinical Therapy Research, the Swedish Heart-Lung Foundation, SFO-V Karolinska Institutet, and the Hesselman Research Foundation; and Thermo Fisher (Uppsala, Sweden) by supplying allergen reagents. Funding information for this article has been deposited with the Crossref Funder Registry.

Conflict of interest: I. Kreyberg has nothing to disclose. K. Hilde has nothing to disclose. K.E.S. Bains has nothing to disclose. K-H. Carlsen has nothing to disclose. B. Granum has nothing to disclose. G. Haugen has nothing to disclose. G. Hedlin has nothing to disclose. C.M. Jonassen has nothing to disclose. L.S. Nordhagen has nothing to disclose. B. Nordlund has nothing to disclose. C.S. Rueegg has nothing to disclose. K.D. Sjøborg has nothing to disclose. H.O. Skjerven has nothing to disclose. A.C. Staff has nothing to disclose. R. Vettukattil has nothing to disclose. K.C. Lødrup Carlsen has received grants as declared in the support statement and an honorarium from Thermo Fisher Scientific for a lecture given at the 2018 EAACI conference.

\section{References}

1 National Center for Chronic Disease Prevention and Health Promotion (US) Office on Smoking and Health. The Health Consequences of Smoking - 50 Years of Progress: A Report of the Surgeon General. 2014, Atlanta, Centers for Disease Control and Prevention (US).

2 Inoue $\mathrm{S}$, Naruse $\mathrm{H}$, Yorifuji $\mathrm{T}$, et al. Impact of maternal and paternal smoking on birth outcomes. J Public Health 2017; 39: 1-10

3 Kharkova OA, Grjibovski AM, Krettek A, et al. Effect of smoking behavior before and during pregnancy on selected birth outcomes among singleton full-term pregnancy: a Murmansk County birth registry study. Int $J$ Environ Res Public Health 2017; 14: E867.

4 Voigt $\mathrm{M}$, Briese $\mathrm{V}$, Jorch $\mathrm{G}$, et al. The influence of smoking during pregnancy on fetal growth. Considering daily cigarette consumption and the SGA rate according to length of gestation. Z Geburtshilfe Neonatol 2009; 213: 194-200.

5 Kvalvik LG, Haug K, Klungsøyr K, et al. Maternal smoking status in successive pregnancies and risk of having a small for gestational age infant. Paediatr Perinat Epidemiol 2017; 31: 21-28.

6 Pereira PP, Da Mata FA, Figueiredo AC, et al. Maternal active smoking during pregnancy and low birthweight in the Americas: a systematic review and meta-analysis. Nicotine Tob Res 2017; 19: 497-505.

7 England LJ, Kendrick JS, Gargiullo PM, et al. Measures of maternal tobacco exposure and infant birth weight at term. Am J Epidemiol; 153: 954-960.

8 Berlin I, Golmard JL, Jacob N, et al. Cigarette smoking during pregnancy: do complete abstinence and low level cigarette smoking have similar impact on birth weight? Nicotine Tob Res 2017; 19: 518-524.

9 Abraham M, Alramadhan S, Iniguez C, et al. A systematic review of maternal smoking during pregnancy and fetal measurements with meta-analysis. PLoS One 2017; 12: e0170946.

10 Bernstein IM, Plociennik K, Stahle S, et al. Impact of maternal cigarette smoking on fetal growth and body composition. Am J Obstet Gynecol 2000; 183: 883-886.

11 Jamal A, Gentzke A, Hu SS, et al. Tobacco use among middle and high school students - United States, 2011-2016. MMWR Morb Mortal Wkly Rep 2017; 66: 597-603.

12 Statistics Norway. Snus More Used than Cigarettes. www.ssb.no/en/helse/artikler-og-publikasjoner/snus-moreused-than-cigarettes. Date last updated: January 18, 2018.

13 Lange S, Probst C, Rehm J, et al. National, regional, and global prevalence of smoking during pregnancy in the general population: a systematic review and meta-analysis. Lancet Glob Health 2018; 6: e769-e776.

14 The National Board of Health and Welfare. Statistics on Pregnancies, Deliveries and Newborn Infants 2016. 2018 www.socialstyrelsen.se/statistik-och-data/statistik/statistikamnen/graviditeter-forlossningar-och-nyfodda

15 Rygh E, Gallefoss F, Reiso H. Use of snus and smoking tobacco among pregnant women in the Agder counties. Tidsskr Nor Laegeforen 2016; 136: 1351-1354. 
Kreyberg I, Bains KES, Carlsen KH, et al. Stopping when knowing: use of snus and nicotine during pregnancy in Scandinavia. ERJ Open Res 2019; 5: 00197-2018.

17 Lambers DS, Clark KE. The maternal and fetal physiologic effects of nicotine. Semin Perinatol 1996; 20: 115-126.

18 Köhler E, Avenarius S, Rabsilber A, et al. Nicotine and its metabolites in amniotic fluid at birth - assessment of prenatal tobacco smoke exposure. Hum Exp Toxicol 2010; 29: 385-391.

19 Kreyberg I, Nordhagen LS, Bains KES, et al. An update on prevalence and risk of snus and nicotine replacement therapy during pregnancy and breastfeeding. Acta Paediatr 2019 108: 1215- 1221.

20 Spindel ER, McEvoy CT. The role of nicotine in the effects of maternal smoking during pregnancy on lung development and childhood respiratory disease. Implications for dangers of E-cigarettes. Am J Respir Crit Care Med 2016; 193: 486-494.

21 Baba S, Wikström AK, Stephansson O, et al. Influence of smoking and snuff cessation on risk of preterm birth. Eur J Epidemiol 2012; 27: 297-304.

22 Baba S, Wikström AK, Stephansson O, et al. Influence of snuff and smoking habits in early pregnancy on risks for stillbirth and early neonatal mortality. Nicotine Tob Res 2014; 16: 78-83.

23 Wikström AK, Cnattingius S, Stephansson O. Maternal use of Swedish snuff (snus) and risk of stillbirth. Epidemiology 2010; 21: 772-778.

24 Gunnerbeck A, Edstedt Bonamy AK, Wikström AK, et al. Maternal snuff use and smoking and the risk of oral cleft malformations - a population-based cohort study. PLoS One 2014; 9: e84715.

25 Gunnerbeck A, Wikström AK, Bonamy AK, et al. Relationship of maternal snuff use and cigarette smoking with neonatal apnea. Pediatrics 2011; 128: 503-509.

26 Nordenstam F, Lundell B, Cohen G, et al. Prenatal exposure to snus alters heart rate variability in the infant. Nicotine Tob Res 2017; 19: 797-803.

27 Gupta PC, Subramoney S, Sreevidya S. Smokeless tobacco use, birthweight, and gestational age: population based, prospective cohort study of 1217 women in Mumbai, India. BMJ 2004; 328: 1538.

28 Juárez SP, Merlo J. The effect of Swedish snuff (snus) on offspring birthweight: a sibling analysis. PLoS One 2013 8: e65611.

29 Lødrup Carlsen KC, Rehbinder EM, Skerjven HO, et al. Preventing Atopic Dermatitis and ALLergies in Children - the PreventADALL study. Allergy 2018; 73: 2063-2070.

30 Favaretto AL, Duncan BB, Mengue SS, et al. Prenatal weight gain following smoking cessation. Eur J Obstet Gynecol Reprod Biol 2007; 135: 149-153.

31 Adegboye AR, Rossner S, Neovius M, et al. Relationships between prenatal smoking cessation, gestational weight gain and maternal lifestyle characteristics. Women Birth 2010; 23: 29-35.

32 Baba S, Wikström AK, Stephansson O, et al. Changes in snuff and smoking habits in Swedish pregnant women and risk for small for gestational age births. BJOG 2013; 120: 456-462.

33 Rode L, Kjærgaard H, Damm P, et al. Effect of smoking cessation on gestational and postpartum weight gain and neonatal birthweight. Obstet Gynecol 2013; 122: 618-625.

34 Barker DJ. The fetal and infant origins of disease. Eur J Clin Invest 1995; 25: 457-463.

35 Koo WW, Walters JC, Hockman EM. Body composition in human infants at birth and postnatally. J Nutr 2000; 130: 2188-2194.

36 D'Angelo S, Yajnik CS, Kumaran K, et al. Body size and body composition: a comparison of children in India and the UK through infancy and early childhood. J Epidemiol Community Health 2015; 69: 1147-1153.

37 George L, Granath F, Johansson AL, et al. Self-reported nicotine exposure and plasma levels of cotinine in early and late pregnancy. Acta Obstet Gynecol Scand 2006; 85: 1331-1337.

38 Kvalvik LG, Nilsen RM, Skjærven R, et al. Self-reported smoking status and plasma cotinine concentrations among pregnant women in the Norwegian Mother and Child Cohort Study. Pediatr Res 2012; 72: $101-107$.

39 Rothman KJ. Epidemiology - An Introduction. New York, Oxford University Press, 2002. 